\title{
ARD
}

Annals of the Rheumatic Diseases

\section{Possible role of HLA-B27 associated cytotoxic T lymphocyte activity in the pathogenesis of the seronegative arthropathies}

The remarkable association between HLA-B27 and the seronegative arthropathies (ankylosing spondylitis, Reiter's syndrome, reactive arthritis) which was uncovered more than 20 years ago, ${ }^{1}$ promised to shed light on the pathogenesis of the spondyloarthropathies. However, despite strong circumstantial evidence for the involvement of certain 'arthritogenic' environmental agents such as Yersinia, Shigella, Klebsiella, Chlamydia and other factors, ${ }^{23}$ the mechanism by which HLA-B27 might play a role in disease pathogenesis is largely unknown.

A clue to the possible involvement of HLA-B27 in the aetiology of ankylosing spondylitis (AS) was provided by the studies of Geczy et al ${ }^{4}$ who showed that cytotoxic $\mathrm{T}$ lymphocytes (CTL), raised by stimulating the peripheral blood mononuclear cells (PBMC) of an HLA-B27 positive clinically normal individual $\left(\mathrm{B}^{2} 7^{+} \mathrm{AS}^{-}\right)$with the PBMC of an HLA identical sibling suffering from AS $\left(\mathrm{B}^{+} 7^{+} \mathrm{AS}^{+}\right)$, will specifically lyse $\mathrm{B} 27^{+} \mathrm{AS}^{+} \mathrm{PBMC}$ but not PBMC from HLA-B27 positive $\left(\mathrm{B}^{2} 7^{+} \mathrm{AS}^{-}\right)$or negative $\left(\mathrm{B}^{-} 7^{-} \mathrm{AS}^{-}\right)$ normal individuals. Moreover the 'disease specific' CTL will lyse $\mathrm{B}^{2} 7^{+} \mathrm{AS}-\mathrm{PBMC}$ that have been modified in vitro with culture filtrate from one of our arthritogenic bacteria (Klebsiella, Salmonella, etc). CTL of similar specificity can also be raised by immunising $B 27^{+} \mathrm{AS}^{-} \mathrm{PBMC}$ with autologous cells modified by certain arthritogenic antigens in vitro. ${ }^{56}$ The failure of a Dutch group to detect CTL to 'modified' B27 determinants ${ }^{7}$ on the cells of their cohort of AS patients is difficult to explain, and the discrepancy between our data and theirs still requires resolution. In related studies, Czitrom et $a l^{8}$ analysed alloreactive CTL clones, specific for HLA-B27, expressed on the cells of normal individuals or of patients with AS. The workers concluded that the conformation of B27 as detected by CTL is identical in normal subjects and AS patients. Such a conclusion is not fully justified, as a recent study demonstrated that peptide induced conformational changes can be detected serologically. ${ }^{9}$ However, our in vitro data were later strengthened by the finding that we could demonstrate, in the peripheral blood of $\mathrm{B} 27^{+} \mathrm{AS}^{+}$patients, ${ }^{10} \mathrm{CTL}$ with specificity for a disease specific determinant. This CTL activity, which was detected in the PBMC of AS patients without the need for in vitro stimulation, was directed against cells from $\mathrm{B} 27^{+} \mathrm{AS}^{+}$patients and from $\mathrm{B}^{2} 7^{+} \mathrm{AS}^{-}$normal individuals whose cells had been 'modified' with bacterial products in vitro. ${ }^{10}$ In contrast, B27 positive ('unmodified') or negative (unmodified or modified) cells from normal individuals were not lysed by these in vivo derived CTL. ${ }^{10}$
We have suggested that CTL in vivo might be involved in the destruction of target tissue bearing HLA-B27 associated determinants and thereby initiate an inflammatory episode. Such an inflammatory mechanism may underlie the pathological features characteristically associated with the HLA-B27 related spondyloarthropathies. ${ }^{11}$ The main difficulty with this possibility is that, so far, no consistent immunological reactivity has been demonstrated in this group of diseases. ${ }^{12}$ Even if the tissues in the axial and peripheral parts of the skeleton express HLA-B27 associated determinants, it remains to be explained why, in AS, the sacroiliac region is affected more frequently than the peripheral joints. However, there are several ways in which cytotoxic mechanisms may be involved in the pathogenesis of AS. First, cells in the sacroiliac region may present to cytotoxic effector cells a more appropriate or 'recognisable' B27-associated peptide complex than cells in the vicinity of the peripheral joints. Second, the activity or concentration of CTL, or both, may be greater in the sacroiliac region. Ultimately, the inflammatory consequences of CTL activity at these sites may be more pronounced than in other parts of the skeleton. More recent review and hypothesis articles ${ }^{13} 14$ have drawn attention to the nature of the $T$ cell repertoire established in the thymus under the influence of B27. It has been suggested that an additional effect of B27 on the $T$ cell repertoire might be to allow the production of B27-restricted $T$ cells (CTL?) which recognise foreign antigens (eg bacterial products), but which cross react with a self antigen, such as a component of the joint.

Qualified support for the concept of a 'diseaseassociated' CTL has been provided by the studies of Hermann and her associates from Germany and the USA, ${ }^{15}$ which indicated that arthritogenic agents such as Yersinia and Salmonella can generate HLA-B27-restricted, bacteria-specific CTL. These workers tested a panel of 354 CD8 positive T lymphocyte clones (TLCs) derived from the synovial fluid of four patients with reactive arthritis and two patients with ankylosing spondylitis. In one patient with yersinia induced arthritis, two TLCs were identified that specifically killed yersinia infected B27 positive target cells. In another patient with salmonella induced arthritis, one B27 restricted CD8 positive TLC that recognised both Salmonella and Yersinia was identified. Further, in five of the six patients, autoreactive CTLs were found, five of which showed B27 restricted killing of uninfected cell lines. It should be noted that, in the studies of Hermann and her associates, the recognition of the B27 molecule 
was not dependent on or associated with disease condition (AS or reactive arthritis). Recently, Gao et $a l^{16}$ demonstrated B27 restricted, collagen specific CTL in the peripheral blood of one patient with reactive arthritis, but not in several others with spondyloarthropathies. These findings, together with our previous demonstration of B27 restricted CTL directed against 'B27-modified determinants ${ }^{4}{ }^{10}$ should provide new insight into the nature of the arthritogenic determinant recognised by $T$ cells and into the significance of this recognition as part of an early event in the initiation of the spondyloarthropathies.

In another approach, transgenic technology was exploited by Taurog et al in an elegant demonstration of the important role played by B27 in the pathogenesis of inflammatory seronegative arthritis. ${ }^{17}$ These workers described the production of transgenic rats that express HLA-B27 and $h \beta_{2}$ m genes, documented the spontaneous appearance of inflammatory disease in these transgenic animals and, furthermore, showed that the B27 transgene product in their rat model was recognised in a conventional manner by allogeneically primed CTL. ${ }^{17}$

Nevertheless, a number of questions remain unanswered. Apart from the issue of why the disease appears localised to certain anatomical sites, it is not clear why some patients have a self limiting form of reactive arthropathy whereas others suffer from more persistent disease. One approach which might clarify some of these questions would involve the isolation, from tissues from as many anatomical sites as possible, of peptides associated with HLA-B $27^{18}$ or associated gene products. The nature of these peptides from clinically normal HLA-B27 positive individuals and from HLA-B27 positive patients at various stages of the disease, might provide a clue to the nature of the arthritogenic peptide which, in association with HLA-B27 or an associated structure, might trigger disease. With regard to HLA-B27 negative patients suffering from AS or one of the other spondyloarthropathies, it would be informative to identify the restricting element(s) and to investigate the possible role CTL may play in this group of individuals.

In the light of recent developments in this area, we wish to propose that a re-examination of the bacterial culture filtrates that contain factors capable of modifying HLA-B27 or associated structures ${ }^{19-21}$ is justified. A similar approach by Starnbach and Bevan ${ }^{22}$ has recently identified a 9-mer peptide of Yersinia which is presented in the context of $\mathrm{H}-2 \mathrm{D}^{\mathrm{b}}$ and is recognised by CTL. Only after a painstaking and thorough study of the nature and role of putative arthritogenic peptides will we be in a position to begin to answer the myriad other questions which have baffled students of the seronegative spondyloarthropathies: for example, what is the explanation for asymmetrical sacroiliitis, what is the aetiopathogenesis of dactylitis and uveitis, and what causes syndesmophyte formation?

Armed with the tools provided by the technological advances in biochemistry and molecular biology, investigators must mount a concerted effort to unravel the molecular and ultimately the cellular basis of the seronegative arthropathies. It is only then that we can seriously contemplate finding answers to the intriguing anatomical location and peculiar features of the spondyloarthropathies. Such studies will provide an important framework for studying the molecular basis of the interaction between HLA-B27, the T cell receptor and peptides from 'arthritogenic bacteria'.

NSW Red Cross Blood Transfusion Service, 153 Clarence Street,

A F GECZY

Sydney NSW 2000, Australia J S SULLIVAN

Correspondence to: A F Geczy.

Brewerton D A, Hart F D, Nicholls A, Caffrey M, James D C O, Sturrock R D. Ankylosing spondylitis and HLA A27. Lancet 1973; 1 904-7.

2 Ahvonen P, Sievers K, Aho K. Arthritis associated with Yersinia enterocolitica infection. Acta Rheumatol Scand 1969; 15: 232-53.

3 Keat A. Reiter's syndrome and reactive arthritis in perspective. $N$ Engl ff Med 1983; 309: 1606-15.

4 Geczy A F, McGuigan L E, Sullivan J S, Edmonds J P. Cytotoxic $\mathrm{T}$ lymphocytes against disease-associated determinant(s) in ankylosing spondylitis. F Exp Med 1986; 164: 932-7.

5 Geczy A F, Alexander K, Bashir H V, Edmonds J P, Upfold L Sullivan J. Klebsiella and ankylosing spondylitis: biological and chemical Sullivan J. Klebsiella and ankylosing spon

6 Prendergast J K, Sullivan J S, Geczy A F, et al. Possible role of enteric organisms in the pathogenesis of ankylosing spondylitis and other seronegative arthropathies. Infect Immun 1983; 41: 935-41.

7 Breur-Vriesendorp B S, Post F A, de Waal L P, et al. Blood lymphocytes from ankylosing spondylitis patients fail to induce disease-specific cytotoxic T-lymphocytes. Hum Immunol 1989; 25: 149-55.

8 Czitrom A A, Pototschnik R, Edwards S, Gladman D D, Falk J A. Analysis of HLA-B27 in ankylosing spondylitis with human alloreactive cytolytic $T$ lymphocyte clones: failure to detect disease-released $T$ cell epitopes. Exp Clin Immunogenet 1986; 3: 129-37.

9 Wang J, Yu D T Y, Fukazawa T, et al. A monoclonal antibody that recognises HLA-B27 in the context of peptides. F Immunol 1994; 152: $1197-205$.

10 Edwards C, Sullivan J, Geczy A, McGuigan L, Edmonds J. 'In vivo' CTL derived from HLA-B27-positive patients with ankylosing spondylitis [abstract]. Australian Society for Immunology 17th Annual Meeting, $1988 ; 179$.

11 Geczy A F, Edwards C M, McGuigan L E, Sulivan J S. Cross-reacting determinants in ankylosing spondylitis. ISI Atlas Immunol 1988; 1: 7-10.

12 McGuigan L E, Geczy A F, Edmonds J P. The immunopathology of ankylosing spondylitis. Semin Arthritis Rheum 1985; 15: 81-105.

13 Scofield R H, Warren W L, Koelsch G, Harley J B. A hypothesis for the HLA-B27 immune dysregulation in spondyloarthropathy: contribution from enteric organisms, B27 structure, peptides bound by B27, and convergent evolution. Proc Natl Acad Sci USA 1993; 90: 9330-4.

14 Gaston J S H. How does HLA-B27 confer susceptibility to inflammatory arthritis? Clin Exp Immunol 1990; 82: 1-2.

15 Hermann E, Yu D T Y, Meyer zum Buschenfelde K-H, Fleischer B. HLA-B27-restricted CD8 T cells derived from synovial fluids of patients with reactive arthritis and ankylosing spondylitis. Lancet 1993; 342: $646-50$.

16 Gao X-M, Wordsworth P, McMichael A. Collagen-specific cytotoxic T lymphocyte responses in patients with ankylosing spondylitis and reactive arthritis. Eur f Immunol 1994; 24: 1665-70.

17 Hammer R E, Malka S D, Richardson J A, Tang J-P, Taurog J D Spontaneous inflammatory disease in transgenic rats expressin HLA-B27 and human $\beta_{2}$ m: an animal model of HLA-B27-associated human disorders. Cell 1990; 63: 1099-112.

18 Wen J, Wang J, Kuipers J G, et al. Analysis of HLA-B`2705 peptide motif, using T2 cells and monoclonal antibody ME1. Immunogenetics 1994; 39: $444-6$.

19 Geczy A F, Alexander K, Bashir H V, Edmonds J. A factor(s) in Klebsiella culture filtrates specifically modifies an HLA-B27-associated cell-surface component. Nature 1980; 283: 782-4.

20 Sullivan J, Upfold L, Geczy A F, Bashir H V, Edmonds J P. Immunochemical characterisation of Klebsiella antigens which specifically modify an HLA-B27-associated cell-surface component. Hum Immunol 1982; 5: 295-307.

21 Upfold L I, Sullivan J S, Geczy A F. Biochemical studies on a facto isolated from Klebsiella K43-BTS1 that cross-reacts with cells from HLA-B27-positive patients with ankylosing spondylitis. Hum Immunol 1986; 17: 224-38.

22 Starnbach $M$ N, Bevan M J. Cells infected with Yersinia present an epitope to class I MHC-restricted CTL. F Immunol 1994; 153: 1603-12. 